\title{
Design of an Information Management System for the Case Library of Business Management Courses
}

\author{
https://doi.org/10.3991/ijet.v16i07.22119 \\ Yi Liang ${ }^{(凶)}$, Bingna Lou \\ Shijiazhuang University of Applied Technology, Shijiazhuang, China \\ yimail1017@126.com
}

\begin{abstract}
The business management models are updated constantly, making it urgent to reform the teaching methods of business management courses (BMCs). Case-based teaching (CBT) is an important way to integrate the teaching and practice of business management. The construction and management of CBT resources has attracted the attention of scholars at home and abroad. This paper designed an information management system for the BMC case library. Firstly, the goals and content were summarized for the construction of the case library and the information management system. Next, the authors designed the BMC case library forms, as well as the function modules of the information management system. There are three core functions in the system: retrieval, cluster analysis, and course case allocation. At last, experimental results verified the effectiveness of the proposed case clustering algorithm and the good test performance of the established system.
\end{abstract}

Keywords-Business management courses (BMCs), case-based teaching (CBT), case library, information management system

\section{$1 \quad$ Introduction}

In current society, as the industrial economy is transforming towards knowledge economy, the business management models are updated constantly [1-2]. To conform to the complexity and uncertainty of the business management models, the reform of the teaching methods of BMCs is also a necessity. As an important and typical teaching method, CBT has always been a good way to integrate the teaching and practice of business management [3-5]. By creating engineering case scenarios, CBT could guide students to master both the theoretical knowledge and practical skills of the engineering cases [6-9]. For this reason, adopting CBT for BMCs is in line with the basic requirements of the cultivation of corporate strategic awareness in the new economic era, and it conforms to the law of the new curriculum reform of BMCs.

At home and abroad, scholars have applied CBT in various fields [10-14], for instance, with the Advanced Software Engineering course as the example, Ahrend et al. [15] designed learning path models for each student based on field model and learner model, and realized personalized learning content recommendation and continuous learning feedback update during the process of iterative learning. Debruyne and De 
Leenheer [16] applied CBT to the politics course in high schools, analyzed the feasibility and value of CBT application, and proposed corresponding implementation suggestions. Aiming that the problems with the application of CBT in the Economic Life course, Tan and Shankaraman [17] proposed a targeted CBT application model with high student participation rate based on learning transfer theory, discovery learning theory and constructivist theory. In terms of the application of CBT in BMCs, Zhu et al. [18] critically reconstructed the connotation of CBT for business management, they proposed a course case development idea oriented at "experience-inquiry", and summarized course elements such as teaching goal, teaching content, teaching mode, and evaluation strategy, etc. Since case library is recognized as an effective teaching tool in the education process, some scholars have designed and developed various case libraries, for example, targeting at the insufficient clustering and high repetition of market supervision cases, Seethamraju [19] designed a market supervision case collection platform based on the Scrapy framework, then, using the KTRM representation method, the author extracted the text information features, calculated the similarity, and constructed the market supervision case library based on the natural language processing technology. With the Modern Technology Management course as an example, Toranzo [20] analyzed the structural elements and description framework of the course and summarized the relevant features and attributes of course case library construction, then, the study accurately classified the resources, and built a new course case library system that is easy to use, rich in resources and diverse in forms and types.

After a careful review of existing literatures, it's found that there are very few existing research papers concerning about the construction of BMC case library, and in the existing ones, the selection of course cases lacked scientific foundations. For this reason, this paper designed an information management system for the BMC case library, and the main research content of this paper includes: the second chapter summarized the goals and content of the construction of BMC case library and the information management system, and elaborated the relationship among case library construction, information management objectives and course implementation process; the third and the fourth chapters respectively designed the BMC case library forms and the function modules of the information management system, the basic structure of the forms was given, and the system had three core functions: retrieval, cluster analysis, and course case allocation. The fifth chapter used experimental results to verify the effectiveness of the proposed case clustering algorithm and the good test performance of the established system.

\section{Goals and Content of the Construction of BMC Case Library and the Information Management System}

The teaching of BMCs has two models: the Chicago theoretical learning model and the case study/practical skill improvement model. The traditional curriculum setting and teaching mode cannot cultivate learners' practical wisdom, and they cannot effectively deal with the complex management environment generated by the non-linear dynamic interactions. The BMC case library and its information management system are 
helpful to the effective construction of professional and practical knowledge system and the dissemination of the knowledge, and they could cultivate learners' ability of practice, expression and thinking when coping with strategic issues or decision-making dilemmas.

The BMC case library and the information management system were constructed under the guidance of the following theories: the management practice theories that emphasize the cultivation of practice and thinking ability, the psychology theories that emphasize self-identification, the knowledge theories that provide evidence for the case selection and organization based on the characteristics of narrative knowledge, and the course theories based on story mode, etc. The goals of library and system construction were defined as enabling the scientific knowledge acquisition of learners, cultivating their ability to reflect on oneself, criticize and learn from others through rational analysis, and transforming learners' self-management awareness through the realization of case connotation and knowledge. Figure 1 shows the relationship among case library construction, information management objectives and course implementation process.

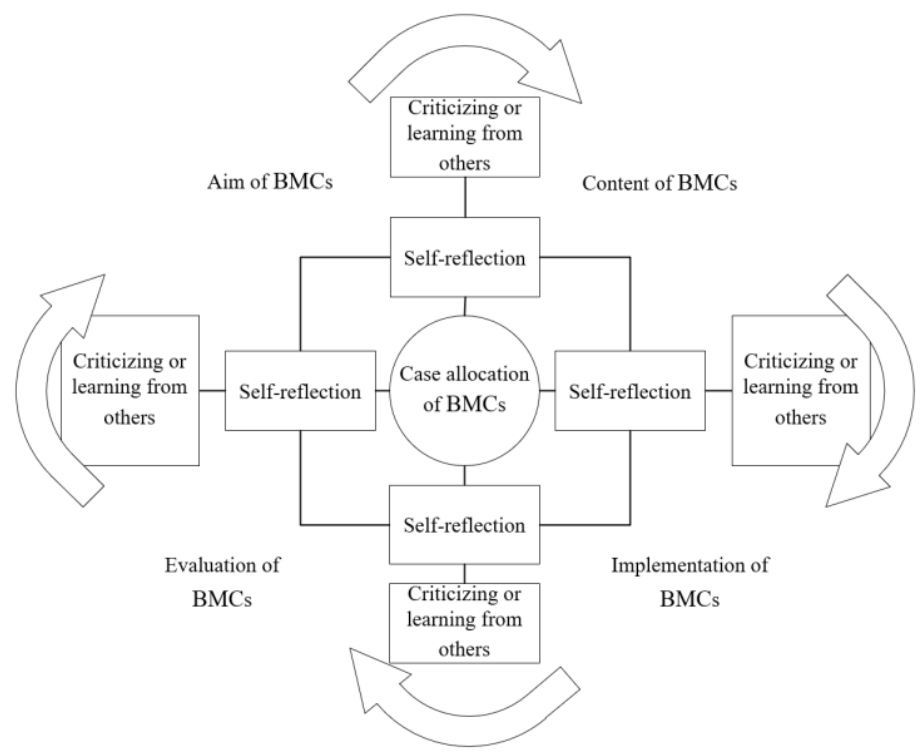

Fig. 1. Relationship among case library construction, information management objectives and course implementation process

If the case library is the content of BMCs, the rationality of the knowledge concept of the cases will determine the value of the cases. The cases in the library should be selected from the perspectives of the narration authenticity, connotation richness, role diversity and practical wisdom. The organization and management of cases in the library should conform to the organizational forms of emergent courses and relational courses, and follow the principles of continuous, rational, and flexible. Then, linear correlations should be constructed among elements such us the teaching goals of BMCs, the selection and organization of cases corresponding to the course content, the course 
implementation, and the effect evaluation, etc., and thus forming a teaching mode with a virtuous cycle of "case analysis - individual study - group discussion - teacher summarization - after-class practice."

\section{Design of BMC Case Library Forms}

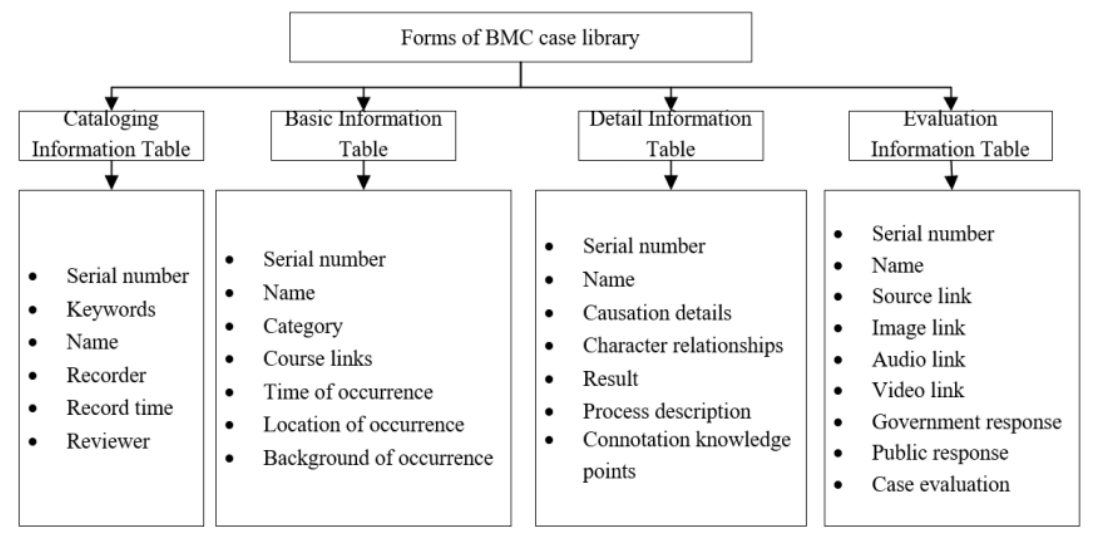

Fig. 2. Basic structure of BMC case library forms

In this study, the cases in the constructed BMC case library were collected by our team members from online searching results of journals, magazines, books, news, and other case information, etc., and the data sources were indicated. The data collection range of this study was the typical domestic and foreign business management related cases from 2005 to the present.

Based on the case selection principles mentioned above, the collected cases need to be classified and organized according to the features of the cases, and then recorded into the system. Figure 2 gives the basic structure of the forms of BMC case library. It includes the Cataloging Information Table which records the case recording status information shown as Table 1; the Basic Information Table which records the basic information of the cases shown as Table 2; the Detail Information Table which records the details of the occurrence of the cases shown as Table 3; and the Evaluation Information Table which records the reports and public comments of the cases shown as Table 4.

Table 1. Cataloging Information Table

\begin{tabular}{|l|l|l|l|l|l|}
\hline \multicolumn{1}{|c|}{ Codename } & \multicolumn{1}{c|}{ Data type } & \multicolumn{1}{c|}{ Remarks } & \multicolumn{1}{c|}{ Codename } & \multicolumn{1}{c|}{ Data type } & \multicolumn{1}{c|}{ Remarks } \\
\hline C_ID & Int & Serial number & C_Key5 & Varchar & Keyword 5 \\
\hline C_Name & Varchar & Name & C_Source & Varchar & Source \\
\hline C_Key1 & Varchar & Keyword 1 & C_Inputer & Varchar & Recorder \\
\hline C_Key2 & Varchar & Keyword 2 & C_Inputdate & Varchar & Record date \\
\hline C_Key3 & Varchar & Keyword 3 & C_Checker & Varchar & Reviewer \\
\hline C_Key4 & Varchar & Keyword 4 & & & \\
\hline
\end{tabular}


Table 2. Basic Information Table

\begin{tabular}{|l|l|l|l|l|l|}
\hline Codename & Data type & \multicolumn{1}{c|}{ Remarks } & \multicolumn{1}{c|}{ Codename } & Data type & \multicolumn{1}{c|}{ Remarks } \\
\hline C_ID & Int & Serial number & C_Time & Varchar & Time of occurrence \\
\hline C_Name & Varchar & Name & C_Place & Varchar & Location of occurrence \\
\hline C_Type & Varchar & Category & C_Background & Varchar & Background of occurrence \\
\hline C_Link & Varchar & Course link & & & \\
\hline
\end{tabular}

Table 3. Detail Information Table

\begin{tabular}{|l|l|l|l|l|l|}
\hline Codename & Data type & \multicolumn{1}{|c|}{ Remarks } & Codename & Data type & \multicolumn{1}{c|}{ Remarks } \\
\hline C_ID & Int & Serial number & C_Result & Text & Result \\
\hline C_Name & Varchar & Name & C_Process & Text & Process description \\
\hline C_Cause & Text & Causation details & C_points & Text & Connotation knowledge points \\
\hline C_Character & Text & Character relationships & & & \\
\hline
\end{tabular}

Table 4. Evaluation Information Table

\begin{tabular}{|l|l|l|l|l|l|}
\hline \multicolumn{1}{|c|}{ Codename } & Data type & \multicolumn{1}{c|}{ Remarks } & \multicolumn{1}{c|}{ Codename } & Data type & \multicolumn{1}{c|}{ Remarks } \\
\hline C_ID & Int & Serial number & C_original & Varchar & Source link \\
\hline C_Name & Varchar & Name & C_Government & Text & Government response \\
\hline C_Image & Varchar & Image link & C_Public & Text & Public response \\
\hline C_Audio & Varchar & Audio link & C_Evaluation & Text & Case evaluation \\
\hline C_Video & Varchar & Video link & & & \\
\hline
\end{tabular}

\section{Design of Function Modules of Information Management System for BMC Case Library}

\subsection{Retrieval function}

In the information management system of BMC case library, the retrieval function mainly includes four sub-functions of keyword retrieval, course type retrieval, relevance retrieval and navigation retrieval. Keyword retrieval includes two retrieval modes: the simple retrieval mode uses case name and keywords to search for cases in the library; the advanced retrieval mode uses case type, course link, time, and information combinations to search for cases in the library.

Using the course type retrieval sub-function, system users can search for cases suitable for multiple courses or different course links of a course. After the course type retrieval requirement is submitted to the system, the system will submit the corresponding retrieval command to the case library, and obtain cases that are suitable for the courses or course links.

The relevance retrieval sub-function is set for professional business management researchers, they can use this function module to set more complex retrieval requirements, this sub-function can be used for application scenarios such as case comparison and case relevance analysis, etc. The difference between the relevance retrieval and the advanced retrieval is that the former one has more search items and it needs to use logical operators shown as Table 5 to construct the search formula. 
Table 5. Examples of relevance retrieval operators

\begin{tabular}{|c|c|c|c|}
\hline Logical operator & Function & Description & Example \\
\hline$=\mathrm{C}_{-} 1 * \mathrm{C}_{-} 2$ & And & Include both keywords C_1 and C_2 & $\begin{array}{l}\text { C_Name = Human resource * } \\
\text { Investment }\end{array}$ \\
\hline$=\mathrm{C}_{-} 1+\mathrm{C} \_2$ & Or & Include keyword C_1 or keyword C_2 & $\begin{array}{l}\text { C_Name= Human resource + } \\
\text { Investment }\end{array}$ \\
\hline$=C_{-} 1-C_{-} 2$ & Not include & $\begin{array}{l}\text { Include key C_1 but not include keyword } \\
\text { C__2 }\end{array}$ & $\begin{array}{l}\text { C_Name= Human resource - } \\
\text { Investment }\end{array}$ \\
\hline $\begin{array}{l}={ }_{\text {C_Retrieval }} \\
\text { items }\end{array}$ & Equal to & Match keyword C_1 accurately & C_Name $=$ Human resource \\
\hline$@ \mathrm{C}_{-}$ & Include & $\begin{array}{l}\text { Include keyword C_1 and word segments } \\
\text { of keyword C__2 }\end{array}$ & $\begin{array}{l}\text { C_Name@ Investment Human } \\
\text { Resource }\end{array}$ \\
\hline
\end{tabular}

According to the case type, the information management system divided the cases in the BMC case library into six main categories: human resource management, sales and marketing, capital operation, business strategy, financial accounting, and corporate governance. In the navigation retrieval sub-function module, the first-level retrieval items were divided into six main categories, the second-level retrieval items were set according to the sub-categories contained in each main category.

The human resource management category included 4 second-level retrieval items: incentive mechanism, salary, human resource system, and performance evaluation; the sales and marketing category included 6 second-level retrieval items: brand development strategy, market analysis, project feasibility study, product development feasibility study, service marketing strategy, and customer survey; the capital operation category included 5 second-level retrieval items: debt restructuring, property rights reform, anti-mergers, equity changes, and convertible bond financing; the business strategy category included 4 second-level retrieval items: continuous expansion strategy, investment opportunity analysis, application of corporate culture construction, and scale expansion strategy; the financial accounting category included 5 second-level retrieval items: financial development strategy, accounting risk prevention strategy, cash dividend plan, enterprise investment analysis, and investment project analysis; the corporate governance category included 2 second-level retrieval items: impact of ownership structure on corporate governance, and ownership structure and governance mechanism.

\subsection{Cluster analysis function}

Cluster analysis is an important function of the proposed system, it can apply cases to different courses or different course links of a same course, it mainly includes keyword cluster of single BMC case and keyword cluster of multiple BMC cases. The purpose of the former is to construct each BMC case to facilitate operations such as reasoning, storage, and retrieval, while the purpose of the latter is to classify the cases according to their similarities and differences, and to find suitable cases or case combinations for course teaching requirements and teaching activity implementation. Figure 3 shows the flow of the cluster analysis function. 


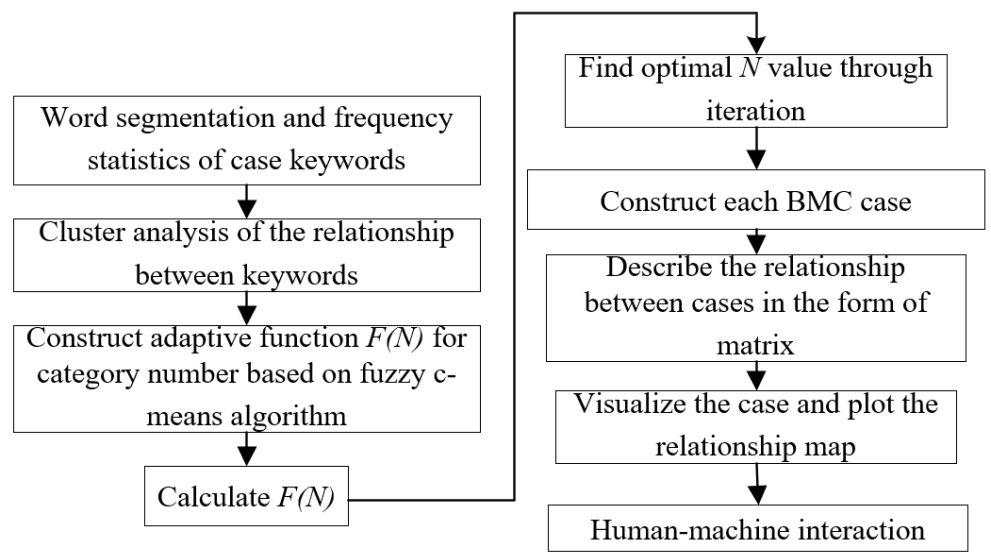

Fig. 3. Flow of the cluster analysis function

The steps of the case clustering method designed in this paper are as follows:

First, use the ICTCLAS software to count word segmentation and frequency of case keywords. For text information such as the descriptions of the process and character relationship of individual cases, the keywords are segmented and sorted according to the frequency.

Then, use the clustering method to analyze the relationship between keywords. The traditional fuzzy $\mathrm{C}$-means algorithm has good clustering effect, but the reliability of the clustering results requires verification, which greatly affected the retrieval and calling speed of cases, therefore, this paper improved the traditional algorithm, clustered a series of case sets and evaluated their application suitability in certain scenarios; this process was equivalent to ensuring relatively large geometric distance between case clusters while the distance between cases within a cluster is relatively small. Assume $\mu_{i j}$ is the degree of membership from the $j$-th BMC case sample to the $i$-th cluster center, then the center vector from the sample to the cluster center can be expressed by Formula 1:

$$
\vec{s}=\frac{\sum_{i=1}^{N} \sum_{j=1}^{M} \mu_{i j}^{R} s_{j}}{N}
$$

where, $N$ is the number of clusters after classification; $M$ is the number of case samples; $R$ is the fuzzy weighted index. The adaptive function of $N$ can be expressed by Formula 2:

$$
F(N)=\frac{\sum_{i=1}^{N}\left(\sum_{j=1}^{M} \mu_{i j}^{R}\right)\left\|C_{i}-\vec{s}\right\|^{2} /(N-1)}{\left(\sum_{i=1}^{N}\left(\sum_{j=1}^{M} \mu_{i j}^{R}\right)\left\|S_{j}-C_{i}\right\|^{2} /(M-N)\right.}
$$


where, $C_{i}$ is the $i$-th cluster center. According to Formula 2, the numerator and denominator of the formula respectively represent the distance between the clusters, and the distance between case within a cluster and the cluster center, that is, the greater the $F(N)$ value, the more reasonable the case cluster; when $F(N)$ value reaches the maximum, $N$ is the optimal value. Figure 4 shows the implementation flow of the improved fuzzy $\mathrm{C}$-means algorithm used in this paper.

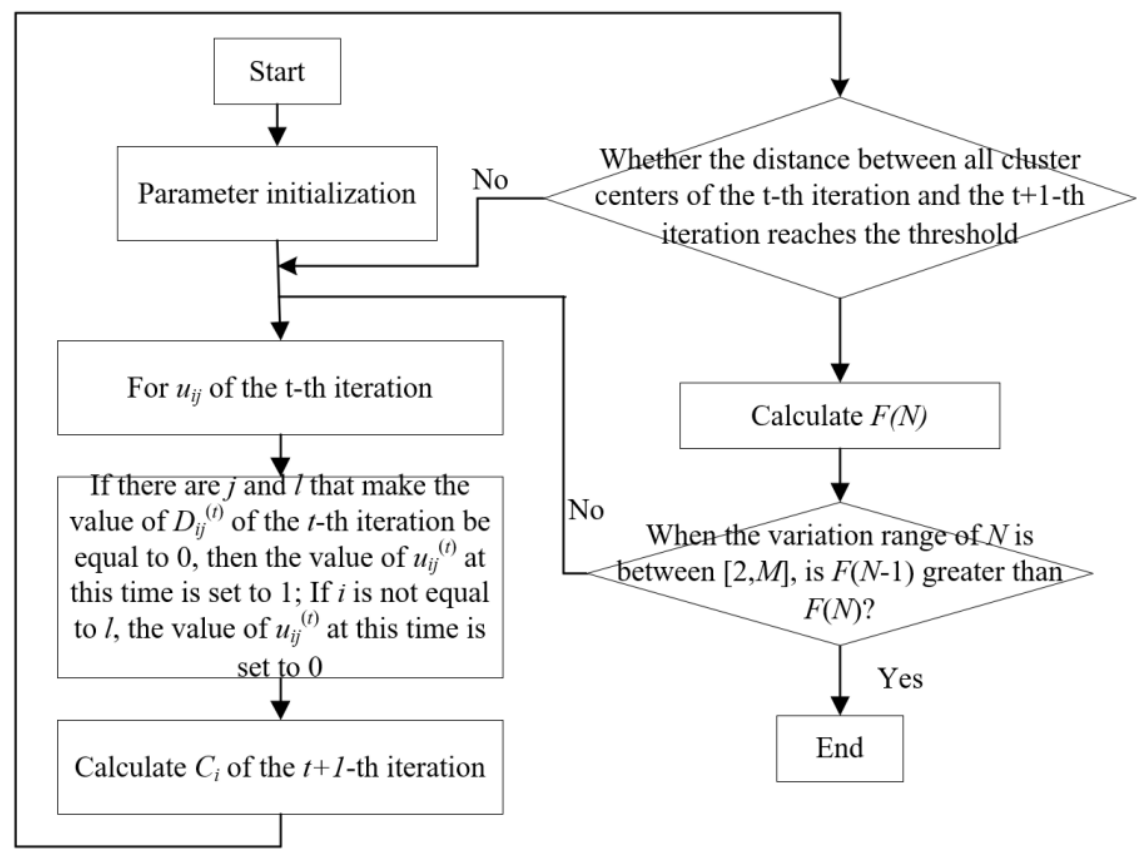

Fig. 4. Implementation flow of the improved fuzzy C-means algorithm

N's self-adaptation steps are:

1. Initialize $\mathrm{N}$ and its adaptive function, cluster center set, and number of clusters, set $F(1)$ and the fuzzy weighting index to 0 , and set $N$ to 2 ;

2. Calculate the $\mu_{i j}$ of the $t$-th iteration using Formula 3:

$$
\mu_{i j}^{(t)}=\frac{1}{\sum_{l=1}^{N}\left(\frac{D_{i j}^{(t)}}{D_{l j}^{(t)}}\right)^{\frac{N}{R-1}}}
$$

where, $D_{i j}$ is the Euclidean distance between case sample $s_{j}$ and cluster center $C_{i}$. If there are $j$ and $l$ that make the value of $\operatorname{Dij}(\mathrm{t})$ of the $t$-th iteration be equal to 0 , then the value of $\mu_{i j}{ }^{(t)}$ at this time is set to 1 . If $i$ is not equal to $l$, the value of $\mu_{i j}{ }^{(t)}$ at this time is set to 0 ; 
3. Calculate the $C_{i}$ of the $t+1$-th iteration using Formula 4:

$$
C_{i}^{(t+1)}=\frac{\sum_{j=1}^{M}\left(\mu_{i j}^{(t)}\right)^{R} s_{j}}{\sum_{j=1}^{M}\left(\mu_{i j}^{(t)}\right)^{R}}
$$

4. Compare the distance between all cluster centers of the $t$-th iteration and the $t+1$-th iteration, if the following Formula is satisfied, the iteration is stopped:

$$
\left\|C^{(t+1)}-C^{(t)}\right\| \leq \varepsilon
$$

where, $\varepsilon$ is the distance threshold. If the formula is not satisfied, order $\mathrm{t}=\mathrm{t}+1$, and return to step 2 .

5. Calculate $F(N)$. When the variation range of $\mathrm{N}$ is between $[2, M]$, if $\mathrm{F}(\mathrm{N}-1)$ is greater than $\mathrm{F}(\mathrm{N})$, the case clustering process terminates; otherwise, order $\mathrm{N}=\mathrm{N}+1$ and return to step 2 .

The above-mentioned clustering algorithm can be used to classify the keywords of specific BMC cases and figure out the relationship between cases, then each BMC case can be constructed and the relationship between cases can be described in the form of matrices. The Ucinet software and the accompanied two-dimensional data analysis tool NetDraw can be used to visualize the cases and plot the relationship map, and the human-computer interaction can be realized by transforming each visualized BMC case into the RDF/OWL language.

\subsection{Course case allocation function}

The course case allocation function can be completed by the case reasoning method, which can solve the problem of cases with similar teaching content by reusing, modifying, and updating the typical course cases, generally, it's divided into two types: explanatory-type case reasoning, and problem-solving case reasoning. The former method compares the clustered cases in the BMC case library with the new courses or course links, and forms a new judgement or conducts re-classification. The latter method directly applies the typical course cases to the new courses or course links, and then forms solutions corresponding to new courses or course links after modification or update.

The solution process of BMC case allocation can be summarized into four steps: case retrieval, case reuse, case modification or update, case preservation and application. Figure 5 gives the specific solution process. When a new course teaching scenario and teaching content requirement is proposed, similar cases in the case library are retrieved according to the keywords of the proposed requirement, and a few solutions of supporting cases could be obtained for this new requirement. If the obtained supporting cases are not good enough, the cases could be adjusted, corrected, or optimized and 
updated by adding new knowledge elements, until a successful supporting case solution could be obtained and saved.

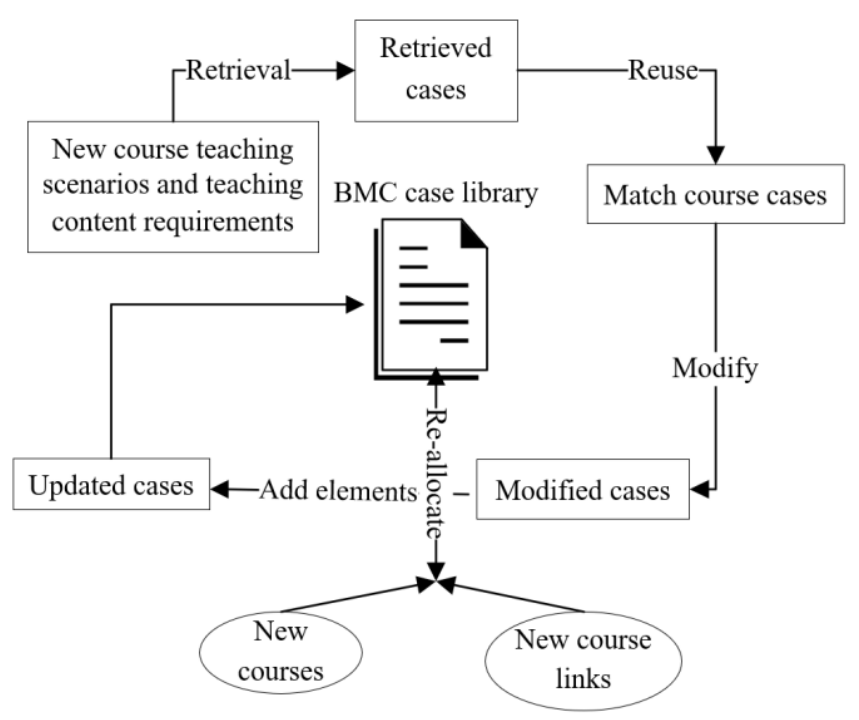

Fig. 5. Solution process of course case allocation

\subsection{Supporting functions}

\begin{tabular}{|c|c|c|c|c|}
\hline \multicolumn{5}{|c|}{ BMC case library } \\
\hline \multicolumn{2}{|c|}{ Serial number } & \multirow{5}{*}{\multicolumn{2}{|c|}{ Process description }} & \multirow{5}{*}{$\begin{array}{l}\text { Character } \\
\text { relationship } \\
\text { description }\end{array}$} \\
\hline Name & & & & \\
\hline Category & & & & \\
\hline Course lir & & & & \\
\hline \multicolumn{2}{|c|}{$\begin{array}{l}\text { Connotation } \\
\text { knowledge point }\end{array}$} & & & \\
\hline Time & & cation & Background & $\begin{array}{l}\text { Causation } \\
\text { details }\end{array}$ \\
\hline Source link & & ge link & Audio link & Video link \\
\hline
\end{tabular}

(a) 


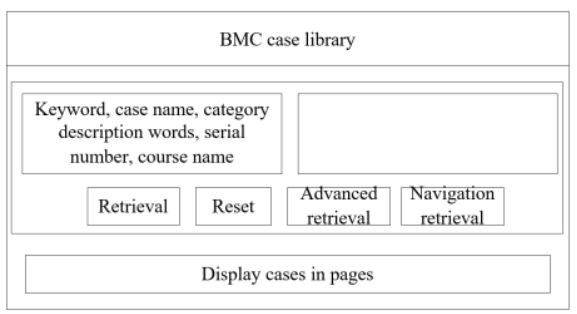

(b)

\begin{tabular}{|c|c|c|c|}
\hline \multicolumn{4}{|c|}{$\mathrm{BMC}$ case library } \\
\hline \multicolumn{3}{|c|}{ Analysis function } & \multirow{2}{*}{$\begin{array}{l}\text { Visualized graphs } \\
\text { and forms }\end{array}$} \\
\hline $\begin{array}{l}\text { Statistics } \\
\text { function }\end{array}$ & $\begin{array}{l}\text { Comparison } \\
\text { analysis }\end{array}$ & $\begin{array}{l}\text { Relevance } \\
\text { analysis }\end{array}$ & \\
\hline \multicolumn{4}{|c|}{ Analysis result: } \\
\hline \multicolumn{4}{|c|}{ Case evaluation: } \\
\hline
\end{tabular}

(c)

Fig. 6. System response interfaces

In addition to the three core functions, the proposed system also has a few sub-modules such as login, registration, system administration, and user management to support normal operation of the system and the safe calling of cases. Figure 6 shows the case display interface, the case retrieval interface, the navigation interface, and the cluster analysis interface. Figure 7 gives the relationship between supporting functions and core functions of the system.

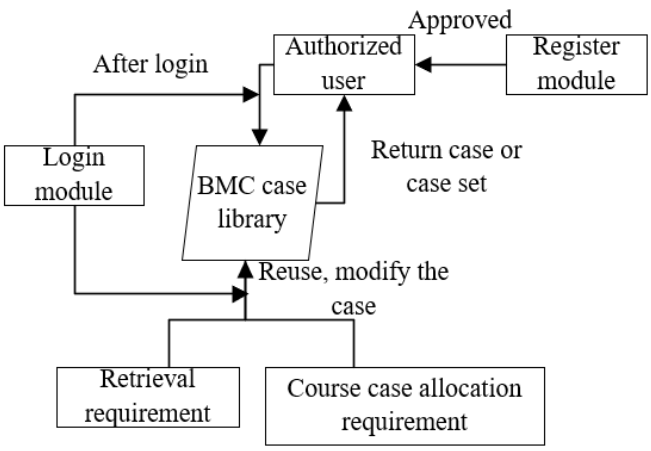

Fig. 7. Relationship between supporting functions and core functions

\section{$5 \quad$ Experimental Results and Analysis}

For the clustering analysis function of the proposed system, this paper gave the flow of the clustering algorithm and designed experiment to verify its effectiveness. Figure 8 shows the clustering effect of 110 cases (the system randomly selected 3 sets of cases from keyword feature intervals $(0,50),(50,100)$, and $(100,150)$ with 30 cases in each case set, and 20 disturbance cases). Figure 8(a) is the case distribution before clustering, and 8 (b) is the case classification after the iterative calculation of the adaptive fuzzy Cmeans algorithm had been completed. The red triangles and squares represent different 
clusters. Through comparison it shows that, the algorithm divided the cases into three groups according to the keyword features.

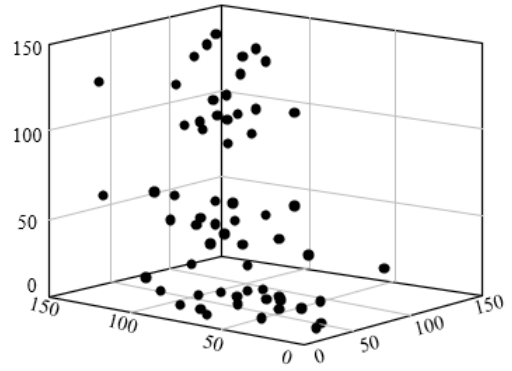

(a)

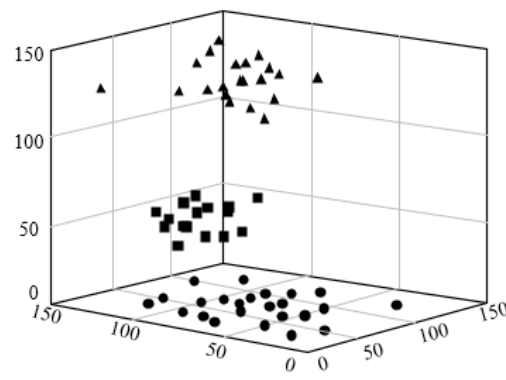

(b)

Fig. 8. Case clustering effect

To facilitate the users to retrieve, call, allocate, add, and modify the cases, during the programming process, cases of different categories could be stored independently, and each category corresponds to a degree of membership $\mu_{i j}$, that is, every case will be classified to the cluster with the greatest $\mu_{i j}$ value. For a case, if the $\mu_{i j}$ values of all categories corresponding to the case are very small, then, based on the case library's simplification requirement, the case needs to be found out, marked, or even removed from the library. This paper set a membership degree threshold $\varepsilon_{D}$ of cases to the clusters. For a case, if its membership degree values to each cluster are all greater than $\varepsilon_{D}$, then it will be classified to the cluster with the greatest membership degree value; if its membership degree values to each cluster are all smaller than $\varepsilon_{D}$, then the case will be removed from the library. The simulation experiments were carried out under the condition of different $\varepsilon_{D}$ values, when $\varepsilon_{D}$ value was $0.4,0.5,0.6$, and 0.7 , the number of cases removed from the library was $3,4,6$, and 9 , respectively.

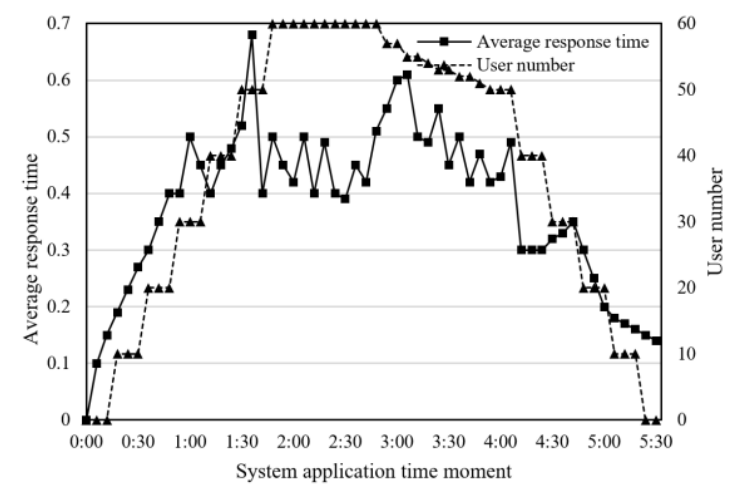

Fig. 9. Relationship between the average response time and the number of concurrent users 
Table 6. System response performance

\begin{tabular}{|c|c|c|c|c|c|c|c|}
\hline \multicolumn{8}{|c|}{ [Retrieval test case] Task } \\
\hline \multirow{2}{*}{$\begin{array}{l}\text { Number of con- } \\
\text { current users }\end{array}$} & \multicolumn{4}{|c|}{\begin{tabular}{l|} 
Response time \\
\end{tabular}} & \multirow{2}{*}{$\begin{array}{l}\text { Response } \\
\text { succeeded }\end{array}$} & \multirow{2}{*}{$\begin{array}{c}\text { Response } \\
\text { failed }\end{array}$} & \multirow{2}{*}{$\begin{array}{l}\text { Response } \\
\text { canceled }\end{array}$} \\
\hline & Minimum & Mean & Maximum & $90 \%$ & & & \\
\hline 60 & 0.052 & 0.413 & 2.475 & 0.72 & 59 & 0 & 1 \\
\hline
\end{tabular}

In the system performance test, the configuration of the server used in the test was: 2GB memory, 120GB Hard disk, CPU Intel Pentium D $2 * 3.4 \mathrm{GHz}$. The configuration of the client-end and performance test host computer was: 1.5GB memory, 80GB Hard disk, CPU Intel Pentium D 1.7GHz. The functions of the proposed system were all tested by the performance testing tool LoadRunner, and the results of each function were basically normal and had no defects.

During the test, a comparative experiment with concurrent users increasing every second was set to test whether the system can have satisfactory click response time under the condition of more concurrent users, at the same time, the function response effect and the server resource occupation status were obtained. Figure 9 gives the relationship between average response time and the number of concurrent users. According to the figure, the average response time increased with the number of concurrent users, and it reached the maximum when there were 60 concurrent users. Table 6 shows the system response performance. According to the table, the maximum response time was $2.475 \mathrm{~s}$, which was less than 5 seconds, and this result satisfied the time performance requirement of the system.

The server resource occupation of the system was not greatly affected by the number of concurrent users, the maximum CPU utilization rate was less than 37\%, the system was relatively stable. During the entire test period, the CPU utilization rate did not exceed $30 \%$, the disk transfer rate was greater than $17 \mathrm{Mb} / \mathrm{s}$, and the memory page swap rate was less than 80 times/s, which had verified the good resource utilization performance of the system.

\section{Conclusion}

This study designed an information management system for BMC case library. At first, the paper summarized the goals and content of the construction of BMC case library and its information management system, and designed the BMC case library forms and the function modules of the information management system. Then, the paper gave the basic structure of the case library forms which include the cataloging information table, the basic information table, the detail information table, and the evaluation information table. The proposed system had three core functions: case retrieval, clustering analysis, and course case allocation. At last, this study designed a comparative experiment to verify the effectiveness of the improved clustering algorithm, and proved that the proposed system had good function performance, time performance and resource utilization performance. 


\section{$7 \quad$ References}

[1] Martins, F., Ribeiro, P., Duarte, F. (2018). Improving project management practice through the development of a business case: A local administration case study. In World Conference on Information Systems and Technologies, pp. 433-448. https://doi.org/10.1007/978-3-31977703-0_43

[2] Yang, D., Niu, S., Cai, Y., Feng, W., Zhang, D. (2020). Analysis of shear characteristics of cohesive soil and rigid base: A case study of concrete base. Geotechnical and Geological Engineering, 39(1), 135-143. https://doi.org/10.1007/s10706-020-01478-0

[3] Ayranci, K., Harris, N.B., Dong, T. (2018). High resolution sequence stratigraphic reconstruction of mud-dominated systems below storm wave base: A case study from the Middle to Upper Devonian Horn River Group, British Columbia, Canada. Sedimentary geology, 373, 239-253. https://doi.org/10.1016/j.sedgeo.2018.06.009

[4] Da Cunha, S., Rangaiah, G.P., Hidajat, K. (2018). Design, optimization, and retrofit of the formic acid process i: Base case design and dividing-wall column retrofit. Industrial and Engineering Chemistry Research, 57(29), 9554-9570. https://doi.org/10.1021/acs.iecr. $\underline{8 b 00883}$

[5] Sandhu, R., Kaur, J., Thapar, V. (2018). An effective framework for finding similar cases of dengue from audio and text data using domain thesaurus and case base reasoning. Enterprise Information Systems, 12(2), 155-172. https://doi.org/10.1080/17517575.2017.1287429

[6] Karmakar, S., Kumar, S., Dutta, S.C., Hussain, A. (2018). Base isolation versus dual design philosophy for seismic design of buildings: preliminary case study. Journal of The Institution of Engineers (India): Series A, 99(4), 627-635. https://doi.org/10.1007/s40030-018-0320-9

[7] Smiti, A., Elouedi, Z. (2018). SCBM: Soft case base maintenance method based on competence model. Journal of Computational Science, 25, 221-227. https://doi.org/10.1016/j.jocs. $\underline{2017.09 .013}$

[8] Lappanitchayakul, K. (2018). Development of email and SMS based notification system to detect abnormal network conditions: A case study of faculty of business administration, rajamangala university of technology Phra Nakhon, Thailand. In 2018 International Conference on Intelligent Informatics and Biomedical Sciences (ICIIBMS), 98-105. https://doi.org/10.1109/iciibms.2018.8549920

[9] Hak, M., Andrlic, B., Sostar, M. (2018). Using information technology in business process re-engineering: Case study of tax administration Croatia. In RTA-CSIT, pp. 160-166.

[10] Pei, J.Y., Shan, P. (2019). A micro-expression recognition algorithm for students in classroom learning based on convolutional neural network. Traitement du Signal, 36(6), 557-563. https://doi.org/10.18280/ts.360611

[11] Xu, Z.H. (2020). Construction and optimization of talent training quality based on data mining. Ingénierie des Systèmes d'Information, 25(4), 419-425. https://doi.org/10.18280/ isi. 250403

[12] Guo, Q. (2020). Detection of head raising rate of students in classroom based on head posture recognition. Traitement du Signal, 37(5), 823-830. https://doi.org/10.18280/ts.370515

[13] Chimhamhiwa, D., van der Molen, P., Mutanga, O., Rugege, D. (2009). Towards a framework for measuring end to end performance of land administration business processes-A case study. Computers, Environment and Urban Systems, 33(4), 293-301. https://doi.org/10.1016/j.compenvurbsys.2009.04.001

[14] Zhang, Z.X., Zhang, M.X. (2020). The reform of ideological and political course online teaching during COVID-19 outbreak a case study of Sichuan technology and business university. in 2020 International Conference on Artificial Intelligence and Education (ICAIE), pp. 320-324. https://doi.org/10.1109/icaie50891.2020.00082 
[15] Ahrend, N., Walser, K., Leopold, H. (2013). Case study of the implementation of business process management in public administration in Germany, Switzerland and Austria. Proceedings of the European Conference on e-Government, ECEG, pp. 11-18.

[16] Debruyne, C., De Leenheer, P. (2012). Business semantics as an interface between enterprise information management and the web of data: A case study in the Flemish public administration. In European Business Intelligence Summer School, pp. 208-233. https://doi.org/ 10.1007/978-3-642-36318-4_9

[17] Tan, K.W., Shankaraman, V. (2014). Hippi Care Hospital: Towards proactive business processes in emergency room services. Journal of Information Systems Education, 25(4), 283288.

[18] Zhu, X., Yan, Y., Sun, X. (2010). Dynamic case teaching and learning: Business education in web-based simulation environment. In 2010 5th International Conference on Computer Science \& Education, pp. 667-670. https://doi.org/10.1109/iccse.2010.5593523

[19] Seethamraju, R. (2006). Teaching e-commerce using an e-business group project - A case study. Proceedings - 2006 SIGED: IAIM 21st Annual Conference, pp. 371-403.

[20] Toranzo, M., Richaud, A., Santander, V. (2017). A proposal for innovation in the teaching of analysis and modeling of business process: Case UCM. In 2017 36th International Conference of the Chilean Computer Science Society (SCCC), pp. 1-12. https://doi.org/10. $\underline{1109 / \mathrm{sccc} .2017 .8405127}$

\section{Authors}

Yi Liang with a master's degree, is the backbone teacher of hotel management major in Shijiazhuang is University of Applied Technology. She has been engaged in teaching for 12 years, and the main research direction is business administration. Email: yimail1017@126.com

Bingna Lou who holds a master's degree is the backbone teacher majoring in hotel managements in Shijiazhuang University of Applied Technology. She is one of the members of Yanzhao Forum Experts. And she started her career in August, 2004 and has been engaged in education for 16 years. Her main research field is business administration. Email: loubn820@126.com

Article submitted 2021-02-17. Resubmitted 2021-03-23. Final acceptance 2021-02-25. Final version published as submitted by the authors. 